\title{
NILAI MANFAAT LANGSUNG EKOSISTEM DIPTEROKARPA \\ BAGI MASYARAKAT SETEMPAT DI HUTAN LINDUNG SUNGAI WAIN
}

(Direct Use Value of Dipterocarp Ecosystem for Local Community

in Sungai Wain Protection Forest)

Oleh/By:

Rujehan

Fakultas Kehutanan Universitas Mulawarman

\begin{abstract}
Sungai Wain Protection Forest (SWPF) is a lowland Dipterocarp forest that provides various benefits to support life and livelihoods for local The research objective is to identify the direct benefits of biological and ecological elements obtained by local community. The research was carried out in the village of Karang Joang North Balikpapan, Balikpapan East Kalimantan. The respondents were 175 local people who use the area. The results showed that biological element collected for the benefit of local communities were fire wood, palm leaves, rattan, bamboo, medicinal plants, grass fodder, honey, aloe, fruit, vegetables, fish and timber. Ecological elements collected by local community was water used for household consumption, sourced from rivers, wells and reservoirs, while agricultural land used for farming activities through a pattern of paddy fields, orchards and mixed gardens. Various products obtained from these two elements are used for own consumption, except for products of the farm and livestock mostly for sale.
\end{abstract}

Key Words : Forest protection, direct benefits, biological elements, ecological elements, local community.

\begin{abstract}
ABSTRAK
Hutan Lindung Sungai Wain (HLSW) adalah hutan Dipterokarpa dataran rendah yang memberikan berbagai manfaat untuk menunjang kehidupan dan penghidupan bagi masyarakat setempat atau petani penggarap. Tujuan penelitian adalah mengidentifikasi manfaat langsung dari unsur biologi dan unsur ekologi yang diperoleh masyarakat setempat. Penelitian ini dilaksanakan di Kelurahan Karang Joang, Balikpapan Utara Kota Balikpapan, Propinsi Kalimantan Timur. Responden penelitian adalah masyarakat setempat yang memanfaatkan kawasan HLSW sebanyak 175 responden. Hasil penelitian menunjukkan, bahwa unsur biologi yang dipungut untuk dimanfaatkan masyarakat setempat adalah kayu (kayu bakar), daun nipah, rotan, bambu, tumbuhan obat, rumput/pakan ternak, madu, gaharu, buah-buahan, sayur-sayuran, ikan dan kayu untuk bahan bangunan. Unsur ekologi yang dipungut untuk dimanfaatkan masyarakat setempat adalah air untuk konsumsi rumah tangga yang bersumber dari sungai, sumur dan waduk, sedangkan lahan pertanian digunakan untuk kegiatan usahatani yang diusahakan melalui pola ladang, kebun buah-buahan dan kebun campuran. Berbagai produk yang diperoleh dari kedua unsur tersebut dimanfaatkan untuk dikonsumsi sendiri (bersifat konsumtif), kecuali produk-produk dari hasil usahatani (ladang, kebun buah-buahan dan kebun campuran) dan ternak sebagian besar untuk dijual (bersifat produktif).
\end{abstract}

Kata Kunci : hutan lindung, manfaat langsung, unsur biologi, unsur ekologi, masyarakat setempat. 


\section{PENDAHULUAN}

\section{A. Latar Belakang}

Hutan sebagai sumberdaya alam yang memberikan manfaat besar bagi kesejahteraan manusia, baik manfaat tangible yang dirasakan secara langsung, maupun intangible yang dirasakan secara tidak langsung. Namun berbagai manfaat ini dapat dirasakan dan dipertahankan apabila hutan dikelola secara benar. Poejaraharjo (1997) dalam Widayanti dan Widodo (1999), hutan yang dikelola dengan baik dengan sendirinya akan meningkatkan fungsinya, baik fungsi produksi maupun fungsi perlindungan. Tetapi hutan yang baik belum tentu mampu memberikan sumbangan langsung yang dibutuhkan bagi manusia di sekitarnya. Simon (1993) menegaskan bahwa manusia memegang peranan penting dalam pengelolaan sumberdaya hutan terlebih untuk masyarakat agraris karena kehidupan mereka lebih banyak tergantung pada ketersediaan lahan garapan.

Pada dasarnya manfaat langsung yang dapat dirasakan dari hutan terdiri dari unsur biologi dan unsur ekologi termasuk ketersediaan lahan pertanian. Unsur-unsur ini seringkali dimanfaatkan untuk menunjang kebutuhan hidup terutama bagi manusia sekitar hutan atau masyarakat setempat. Istilah masyarakat setempat dijelaskan dalam Undang-undang No. 41 Tahun 1999 tentang Kehutanan ialah kesatuan sosial yang terdiri dari warga negara Republik Indonesia yang tinggal di dalam dan/atau di sekitar hutan, yang membentuk komunitas yang didasarkan pada mata pencaharian yang berkaitan dengan hutan, kesejarahan, keterikatan tempat tinggal, serta pengaturan tata tertib kehidupan bersama. Oleh karena itu pengertian ini mengisyaratkan adanya ketergantungan masyarakat setempat dengan hutan melalui pemanfaatan unsur-unsur tersebut.

Ketergantungan masyarakat setempat terhadap hutan sebenarnya sudah berlangsung lama. Hasil penelitian Uluk, Sudana dan Wollenberg (2001) menyatakan, bahwa masyarakat setempat di kawasan Taman Nasional Kayan Mentarang (TNKM) sangat tergantung pada berbagai jenis hasil hutan. Dari hasil perhitungan data tercatat sebanyak 139 sampai 214 jenis hasil hutan yang dimanfaatkan untuk berbagai kepentingan dalam waktu 1 (satu) tahun (1995-1996). Berbagai kepentingan yang dimaksud antara lain sebagai sumber makanan, obat, bahan bangunan, sumber penghasilan uang tunai, upacara dan kebudayaan.

Tentu saja orientasi dan motivasi ketergantungan tersebut tidak akan sama antar generasi atau antara satu kelompok masyarakat di suatu wilayah dengan kelompok masyarakat di wilayah lainnya. Demikian juga antara kelompok masyarakat asli (Dayak) dan masyarakat pendatang seringkali berbeda baik orientasi kebutuhan terhadap hasil hutan maupun tujuan pemanfaatannya. Kondisi ini senantiasa berubah sesuai dengan perkembangan budaya dan perekonomian seiring dengan keterbukaan wilayah sebagai dampak pembangunan.

Hutan Lindung Sungai Wain (HLSW) terletak di wilayah administratif Kota Balikpapan Propinsi Kalimantan Timur memiliki luas 9.783 hektar. Hutan ini merupakan tipe hutan Dipterokarpa dataran 
rendah (Anonymous, 2010), dimana jenis pohon kanopi dominan yang masih terdapat di hutan tua adalah Bangkirai (Shorea laevis), Ulin (Eusideroxylon zwageri) dan Gaharu (Aquilaria malaccensis).

Keberadaan HLSW saat ini disamping sebagai zona penyangga untuk masyarakat kota Balikpapan juga menjadi sumber penghidupan oleh sebagian masyarakat setempat. Seiring dengan perkembangan jumlah penduduknya yang semakin pesat (periode 2002-2007 naik 35,58\%), sehingga membutuhkan tambahan ruang untuk hidup (pemukiman dan lahan pertanian), juga semakin terbatasnya lapangan pekerjaan di wilayah tersebut. Kondisi ini berefek pada kawasan HLSW sebagai sasaran untuk memenuhi kebutuhan rumah tangga. Potensi apa saja yang terkandung dalam kawasan HLSW bagi pemenuhan kebutuhan tersebut masih belum terungkap secara pasti. Sehingga melalui penelitian ini, dicoba mengidentifikasi nilai manfaat langsung apa saja dari HLSW yang memberikan kontribusi bagi kehidupan dan penghidupan masyarakat setempat. Berkaitan hal tersebut, tujuan penelitian ini adalah mengidentifikasi nilai-nilai manfaat langsung dari unsur biologi dan unsur ekologi bagi komunitas masyarakat setempat. Hasil penelitian yang disajikan dalam makalah ini diharapkan sebagai bahan informasi dan sekaligus menjadi perhatian semua pihak dalam rangka turut berpartisipasi menyelamatkan ekosistem hutan yang bermanfaat bagi kehidupan dan penghidupan.

\section{B. Lokasi Penelitian}

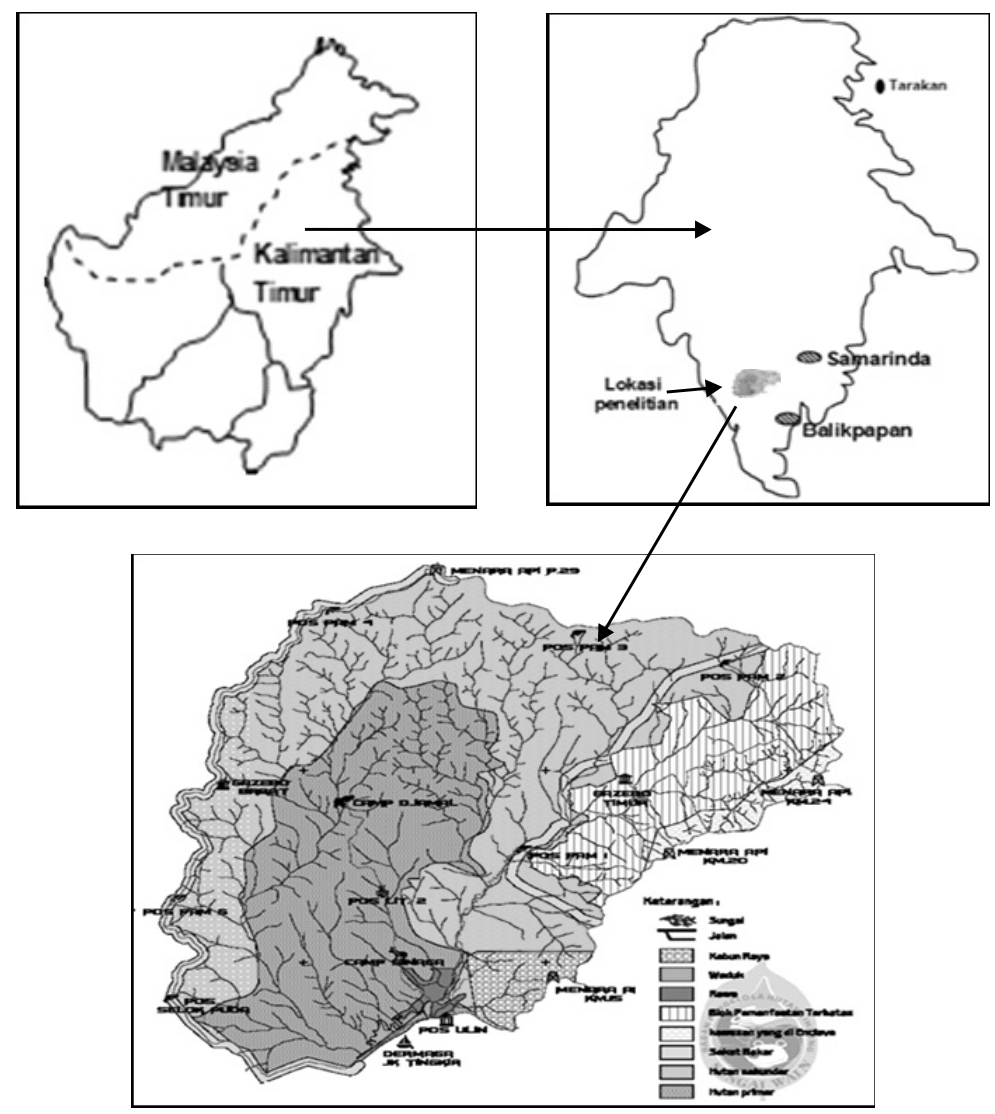

Sumber: Badan Pengelola HLSW, 2008 (Source: Management Board of HLSW, 2008)

Gambar 1. Peta Lokasi Penelitian (Pigure 1. Map of Study Site) 
Penelitian ini dilaksanakan di kawasan Hutan Lindung Sungai Wain (HLSW). Wilayah ini secara administratif pemerintahan terletak di Kecamatan Balikpapan Utara dan Kecamatan Balikpapan Barat, Wilayah Kota Balikpapan Propinsi Kalimantan Timur (Gambar 1). Alasan dipilihnya lokasi tersebut karena diantara hutan-hutan lindung yang ada di Kalimantan Timur, HLSW merupakan kawasan hutan lindung yang paling rawan mengalami deforestasi dan degradasi hutan, mengingat aksesibilitas yang sangat tinggi ke wilayah itu. Di sisi lain fungsi ekosistem HLSW sangat menunjang bagi kehidupan masyarakat setempat dan Kota Balikpapan.

\section{METODOLOGI}

Obyek penelitian ini adalah ekosistem Dipterokarpa HLSW beserta interaksinya terhadap kegiatan masyarakat setempat dalam kurun waktu antara Desember 2008 dan Mei 2009. Oleh karena itu, sampel penelitian ini adalah para pemanfaat dari masyarakat setempat yang mempunyai interaksi dengan keberadaan sumberdaya ekosistem tersebut. Tentang besarnya sampel, Soekartawi (1995) menyatakan tergantung dari tingkat homogenitas populasi. Jika kondisi populasi homogen, maka masalah jumlah sampel tidak menjadi persoalan. Tetapi jika kondisi populasi heterogen, maka jumlah sampel harus cermat dan tepat. Untuk itu Parel et al. (1973) telah mempertimbangkan hal tersebut sehingga jumlah sampel (n) ditentukan dengan rumus sebagai berikut:

$$
\mathrm{n}=\frac{\mathrm{NZ}^{2} \sigma^{2}}{\mathrm{Nd}^{2}+\mathrm{Z}^{2} \sigma^{2}}
$$

Keterangan:

$\mathrm{n}=$ jumlah sampel

$\mathrm{N}=$ populasi

$\mathrm{Z}=$ nilai $\mathrm{Z}$ dari tabel $\mathrm{Z}$ pada tingkat kepercayaan $95 \%$

$\mathrm{s}^{2}=$ ragam populasi

$\mathrm{d}^{2}=$ penyimpangan yang dapat diterima $5 \%$

Karena $\sigma^{2}$ tidak diketahui maka dalam penelitian ini ditaksir dengan cara melakukan pre-survei terhadap pendapatan total rumah tangga masyarakat setempat dengan sampel sebanyak 50 responden yang diambil secara acak, kemudian keragaman $\left(\mathrm{s}^{2}\right)$ yang diperoleh dari sampel tersebut diperlukan untuk menaksir $\sigma^{2}$.

Setelah dilakukan perhitungan dengan menggunakan rumus tersebut di atas telah dihasilkan sebanyak 174 sampel Kepala Keluarga (KK). Dalam penelitian ini jumlah sampel yang diwawancarai sebanyak 175 KK sehingga sudah memenuhi syarat minimal statistik. Dengan demikian diharapkan dapat merepresentasikan populasi.

Jenis data yang dikumpulkan terdiri dari data primer dan data sekunder. Sumber data primer atau data utama dikumpulkan dari para responden terpilih (masyarakat setempat) dan biofisik HLSW. 
Teknik yang dipakai dalam pengumpulan data primer adalah teknik wawancara langsung dan observasi lapangan (field observation) melalui dokumentasi kondisi biofisik kawasan. Sumber data sekunder atau data penunjang dikumpulkan dari Badan Pengelola HLSW (BPHLSW) dan Kelurahan Karang Joang. Untuk melengkapi data penunjang yang dimaksud juga telah dikumpulkan melalui studi kepustakaan, informasi yang bersumber dari jurnal/laporan penelitian (media cetak dan elektronik/internet), seperti yang disebutkan dalam daftar pustaka.

\section{HASIL DAN PEMBAHASAN}

Posisi HLSW sangat strategis untuk penghidupan dan kehidupan masyarakat Balikpapan. Hutan ini merupakan sebuah contoh unik dan khas dari tipe hutan Dipterokarpa dataran rendah, yang dulunya menutupi hampir seluruh wilayah antara Balikpapan-Samarinda (Anonimous, 2010). Dijelaskan lebih lanjut bahwa jenis pohon kanopi dominan di hutan tua adalah Bangkirai (Shorea laevis), Ulin (Eusideroxylon zwageri) dan Gaharu (Aquilaria malaccensis) ternyata masih banyak terdapat di kawasan ini. Selain dari jenis pohon kanopi tersebut, HLSW juga mempunyai keragaman jenis yang tinggi untuk jenis-jenis epifit (anggrek), pakis dan tumbuhan merambat. Selain itu, ditemukan juga spesies jahe raksasa yang diberi nama Jahe Balikpapan (Etlingera Balikpapanensis), salah satu spesies baru tumbuhan jahe-jahean yang sampai saat ini hanya dapat ditemukan di HLSW.

Disamping HLSW memiliki keunikan dan kekhasan seperti yang diuraikan di atas, ternyata banyak masyarakat setempat yang masih memanfaatkan kawasan HLSW sebagai penunjang kebutuhan hidup sehari-hari. Unsur-unsur yang dimanfaatkannya tidak hanya dari unsur biologi, tetapi juga dari unsur ekologi. Berikut dibahas lebih dalam, jenis dan pemanfaatan dari kedua unsur tersebut oleh masyarakat setempat.

\section{A. Unsur Biologi}

Unsur biologi yang diperoleh masyarakat setempat dari kawasan HLSW adalah terdiri dari: kayu bakar, daun nipah, rotan, bambu, tumbuhan obat, rumput/pakan ternak, lebah madu, gaharu, buah-buahan, sayur-sayuran, satwa ikan dan bahan bangunan. Secara jelas berikut disampaikan persentase responden yang memanfaatkan unsur biologi tersebut dan peruntukannya (Tabel 1).

Tabel 1 menunjukkan bahwa pemanfaat kayu bakar paling dominan di kawasan HLSW yaitu sebesar 53\% dari total responden. Dominannya pemanfaat kayu bakar di wilayah masyarakat sekitar HLSW mengindikasikan kondisi masyarakatnya yang miskin. Pilihan kayu bakar untuk energi rumah tangga didorong karena melambungnya harga minyak tanah di wilayah tersebut hingga mencapai Rp. 10.000,- per liter, dan hal ini tentu cukup berat bagi rumah tangga miskin untuk mendapatkannya dengan kondisi dana yang sangat terbatas. Nugroho, Undaharta dan Siregar (2008) menyatakan dari hasil penelitiannya di wilayah Bedugul-Pancasari Bali bahwa kondisi pendapatan masyarakat yang 
rendah menjadi salah satu penyebab mengambil sumberdaya hayati kayu bakar sebagai sarana memasak.

Iabel (lable)1. Persentase Kesponden remantaat Unsur B1olog1 dan reruntukannya (Percentage of Respondents Utilization of Biological Elements and Their Purpose)

\begin{tabular}{|c|c|c|c|c|c|}
\hline $\begin{array}{l}\text { Nomor/ } \\
\text { Number }\end{array}$ & Unsur Biologi/Biological Elements & $\begin{array}{c}\text { Total } \\
\text { Responden/ } \\
\text { Number of } \\
\text { Respondents }\end{array}$ & $\begin{array}{c}\text { Jumlah } \\
\text { Responden } \\
\text { Pemanfaat/ } \\
\text { Number of } \\
\text { Respondents } \\
\text { Utilizing }\end{array}$ & $\%$ & Peruntukannya/Use \\
\hline 1 & Kayu Bakar & 175 & 92 & 53 & Bahan bakar untuk memasak \\
\hline 2 & Daun Nipah & 175 & 7 & 4 & Bahan baku untuk atap daun \\
\hline 3 & Rotan & 175 & 11 & 6 & Bahan baku untuk atap daun \\
\hline 4 & Bambu & 175 & 20 & 11 & Bahan baku untuk atap daun \\
\hline 5 & Tumbuhan Obat & 175 & 10 & 6 & $\begin{array}{l}\text { Untuk penyembuhan berbagai } \\
\text { penyakit dan bumbu masak }\end{array}$ \\
\hline 6 & $\begin{array}{l}\text { Rumput/Pakan } \\
\text { Ternak }\end{array}$ & 175 & 4 & 2 & $\begin{array}{l}\text { Untuk makanan ternak } \\
\text { kambing }\end{array}$ \\
\hline 7 & Lebah Madu & 175 & 3 & 2 & $\begin{array}{l}\text { Penghasil madu dan } \\
\text { dikonsumsi sendiri }\end{array}$ \\
\hline 8 & Gaharu & 175 & 2 & 1 & $\begin{array}{l}\text { Untuk acara-acara ritual dan } \\
\text { pengharum ruangan }\end{array}$ \\
\hline 9 & Buah-buahan & 175 & 22 & 13 & $\begin{array}{l}\text { Dikonsumsi langsung } \\
\text { (subsistens) }\end{array}$ \\
\hline 10 & Sayur-sayuran & 175 & 12 & 7 & Untuk menu masakan \\
\hline 11 & Satwa Ikan & 175 & 53 & $\overline{30}$ & Untuk menu masakan \\
\hline 12 & Bahan Bangunan & 175 & 17 & 10 & Untuk membangun pondok \\
\hline
\end{tabular}

Sumber: Data Primer, 2009 (Source: Primary Data, 2009)

Kayu yang dimanfaatkan untuk kayu bakar oleh masyarakat sekitar HLSW bukan dari hasil penebangan kayu yang masih baik, tetapi memanfaatkan kayu dari pohon yang sudah tumbang atau mati dan bagian-bagian tumbuhan lainnya seperti ranting. Kebanyakan kayu bakar yang dimanfaatkan bersumber dari kayu hasil penanaman (hasil rehabilitasi lahan) yang sudah tumbang seperti jenis akasia dan karet.

Selanjutnya para pemanfaat ikan juga cukup dominan yaitu sebanyak $30 \%$ dari total responden. Seperti diketahui bahwa masyarakat yang bermukim di sekitar HLSW adalah kelompok masyarakat pendatang (migran) yang didominasi oleh suku Bugis, Jawa dan Banjar. Masyarakat Bugis dan Banjar umumnya suka mengkonsumsi ikan segar. Dengan kondisi karakteristik wilayah HLSW yang banyak memiliki sungai besar maupun kecil serta keberadaan waduk, sehingga masyarakat tersebut dengan mudah mendapatkan ikan segar melalui memancing maupun menjala. Jenis-jenis ikan yang terdapat di sungai mapun di waduk antara lain; ikan gabus (Ophiocephalus striatus), lele panjang/limbat (Clarias nieuhofii), lele pendek (Clarias batrachus), belut sungai (Monopterus albus), patin (Pangasius hypophthalmus), baung (Hemibragus nemurus), seluang (Osteochillus schlegeli), sepat (Trichogaster trichopterus), nila (Oreochromis niloticus) dan lain-lain.

Sementara pemanfaat jenis buah-buahan juga cukup dominan atau 13\% dari total responden. Cukup dominannya masyarakat memanfaatkan jenis buah-buahan karena lokasi pemungutannya tidak jauh dari pemukiman yaitu sekitar $2 \mathrm{~km}$. Pohon-pohon buah yang terdapat di wilayah HLSW sebagian 
besar dari hasil penanaman yang sudah tidak terurus. Jenis buah-buahan yang terdapat di kawasan HLSW antara lain: cempedak hutan (Artocarphus kemando), durian hutan (Durio oxejanus), rambutan (Nephelium lappaceum), lai (Durio kutejensis), langsat (Lansium domesticum), nangka (Artocarpus heterophyllus), rambai (Strychonos laurina), sirsak (Annona muricata) dan lain-lain.

Selanjutnya pemanfaatan bambu oleh masyarakat setempat juga cukup dominan atau $11 \%$ dari total responden. Penggunaan bambu tidak hanya untuk turus tanaman tetapi juga untuk tulang atap daun. Jenis bambu untuk turus tanaman adalah jenis bambu waluh (Schizostachyum mosum) dengan bentuk batangnya lurus, kecil dan tidak bercabang sehingga sangat baik digunakan untuk turus tanaman. Sementara jenis bambu yang digunakan untuk tulang atap daun adalah jenis bambu pring/lokal (Bambusa vulgaris Schrad.). Bambu yang diusahakan ini tidak hanya untuk memenuhi kebutuhan yang bersifat subsisten tetapi juga untuk komersial secara terbatas.

Sementara pemanfaat kayu bangunan terdapat $10 \%$ dari total responden. Pemanfaatan kayu bangunan didominasi oleh petani yang memiliki lahan usahatani dalam kawasan pemanfaatan. Kayu tersebut digunakan hanya untuk membangun pondok ladang dan tidak untuk komersial. Jenis kayu yang dimanfaatkan masyarakat untuk digunakan sebagai bahan bangunan diantaranya kayu marpu'ung (Macaranga spp.).

Pemanfaat gaharu adalah paling sedikit dari sekian unsur biologi yang dimanfaatkan masyarakat setempat yaitu hanya 1\% dari total responden. Pada dasarnya jenis pohon gaharu (spesies Aquilaria malaccensis) cukup banyak terdapat di kawasan HLSW, namun pohon ini sangat dilindungi. Oleh karena itu meskipun nilai gaharu sangat menjanjikan untuk menghasilkan pendapatan, namun masyarakat tidak boleh leluasa memanfaatkannya. Keberadaan pohon gaharu di kawasan tersebut untuk tujuan konservasi. Masyarakat yang memanfaatkan pohon gaharu di kawasan tersebut dilakukan secara sembunyi-sembunyi yang tentunya ini merupakan pemanfaatan ilegal.

Dari sekian pemanfaatan unsur biologi yang ada di atas (Tabel 1) ternyata tidak ditemukan untuk kepentingan upacara dan kebudayaan sebagaimana yang terdapat pada masyarakat asli (Dayak) sekitar TNKM. Pemanfaatan unsur biologi di wilayah masyarakat tersebut antara lain; sebagai sumber makanan, obat-obatan, bahan bangunan, sumber penghasilan uang tunai, upacara dan kebudayaan dan sebagai sumber bahan baku untuk perlengkapan sehari-hari termasuk memperoleh kayu bakar (Uluk, Sudana dan Wollenberg, 2001). Pemanfaatan unsur biologi untuk kepentingan upacara dan kebudayaan oleh masyarakat asli (Dayak) merupakan warisan secara turun temurun. Keberadaan hutan dianggap tidak hanya sebagai sumber pemenuhan kebutuhan dari aspek ekonomi saja tetapi juga untuk pemenuhan aspek sosial budaya. Sementara untuk masyarakat pendatang seperti masyarakat yang ada di sekitar HLSW, keberadaan hutan hanya sebagai penunjang untuk memenuhi kebutuhan aspek sosial ekonomi. Kondisi masyarakat yang beragam di wilayah tersebut dengan latar belakang budaya yang berbeda (bukan masyarakat asli) menyebabkan hutan tidak dimanfaatkan untuk kepentingan sosial budaya. 


\section{B. Unsur Ekologi}

Unsur ekologi yang diperoleh masyarakat setempat dari kawasan HLSW adalah terdiri dari air dan lahan pertanian. Secara jelas berikut disampaikan persentase responden yang memanfaatkan unsur tersebut dan peruntukannya (Tabel 2).

Tabel (Table) 2. Persentase Responden Pemanfaat Unsur Ekologi dan Peruntukannya (Percentage of Respondents Utilization of Ecological Elements and Their Purpose)

\begin{tabular}{|c|c|c|c|c|l|}
\hline $\begin{array}{c}\text { Nomor/ } \\
\text { Number }\end{array}$ & $\begin{array}{c}\text { Unsur Ekologi/ } \\
\text { Ecological Elements }\end{array}$ & $\begin{array}{c}\text { Total } \\
\text { Responden/ } \\
\text { Number of } \\
\text { Respondents }\end{array}$ & $\begin{array}{c}\text { Jumlah } \\
\text { Responden } \\
\text { Pemanfaat/ } \\
\text { Number of } \\
\text { Respondents } \\
\text { Utilizing }\end{array}$ & $\%$ & Peruntukannya/Use \\
\hline 1 & Air Kawasan & 175 & 175 & 100 & $\begin{array}{l}\text { Untuk mandi cuci kakus (MCK), air minum dan } \\
\text { menyiram tanaman }\end{array}$ \\
\hline 2 & Lahan Pertanian & 175 & 67 & 38 & Untuk kegiatan usahatani \\
\hline
\end{tabular}

Sumber: Data Primer, 2009 (Source: Primary Data, 2009)

Tabel 2 menunjukkan bahwa seluruh responden (100\%) memanfaatkan sumber air yang ada dalam kawasan HLSW. Kondisi ini terjadi karena hingga kini masyarakat setempat belum memperoleh suplai air dari Perusahaan Daerah Air Minum (PDAM) Kota Balikpapan. Sehingga untuk memenuhi kebutuhan air rumah tangga, masyarakat memperoleh dan memanfaatkan air dari kawasan HLSW. Air yang diperoleh tersebut bersumber dari 3 (tiga) sumber, yaitu sungai, sumur dan waduk. Ada sekelompok masyarakat tidak hanya memanfaatkan air dari satu sumber saja tetapi juga lebih dari satu sumber, diantaranya seperti sumur kombinasi dengan sungai dan sumur kombinasi dengan waduk (Tabel 3).

Tabel (Table) 3. Persentase Responden Memperoleh Air Berdasarkan Sumbernya (Percentage of Respondents by Source of Water Obtained)

\begin{tabular}{|c|l|c|c|c|}
\hline $\begin{array}{c}\text { Nomor/ } \\
\text { Number }\end{array}$ & Sumber/Source & $\begin{array}{c}\text { Total } \\
\text { Responden/ } \\
\text { Number of } \\
\text { Respondents }\end{array}$ & $\begin{array}{c}\text { Jumlah } \\
\text { Responden Pemanfaat/ } \\
\text { Number of } \\
\text { Respondents Utilizing }\end{array}$ & $\%$ \\
\hline 1 & Sumur & 175 & 88 & 50,29 \\
\hline 2 & Waduk & 175 & 63 & 36,00 \\
\hline 3 & Sungai & 175 & 3 & 1,71 \\
\hline 4 & Sumur dan Waduk & 175 & 1 & 0,57 \\
\hline 5 & Sumur dan Sungai & 175 & 20 & 0,00 \\
\hline 6 & Waduk dan Sungai & 175 & 0 & 0,00 \\
\hline 7 & Sumur, Sungai dan Waduk & 175 & 0 & \\
\hline
\end{tabular}

Sumber: Data Primer, 2009 (Source: Primary Data, 2009)

Tabel 3 menunjukkan pemanfaatan sumber air sumur oleh masyarakat setempat paling dominan atau lebih dari 50\% (50,29\%), kemudian diikuti dengan waduk sebanyak 36\%, sumur dan sungai $11,43 \%$, sungai $1,71 \%$ dan sumur dan waduk hanya sebanyak $0,57 \%$. Kondisi ini dikarenakan 
pertimbangan lokasi waduk dan sungai yang terpusat di suatu tempat, sehingga pilihan untuk memperoleh kebutuhan air dengan cara membuat sumur di sekitar rumah.

Selanjutnya jumlah responden yang memanfaatkan kawasan untuk lahan pertanian sebanyak 38\% dari total responden (Tabel 2). Tidak semua masyarakat yang melakukan kegiatan ini karena tidak adanya pembukaan lahan baru untuk para pendatang belakangan. Masyarakat yang boleh memanfaatkan lahan kawasan hanya masyarakat yang sudah terdata pada tahun 2004 dimana pada saat Peraturan Daerah (PERDA) HLSW disahkan dan diterbitkan. Masyarakat yang terdata ini adalah masyarakat yang sebelumnya telah melakukan perambahan/okupasi lahan HLSW.

\section{Usahatani}

Usahatani yang dilakukan masyarakat setempat (petani) berlokasi di dalam kawasan pemanfaatan HLSW. Menurut Anonymous (2003), luas kawasan tersebut adalah 1.100 hektar. Dari luas kawasan yang ada, ternyata lahan yang telah diusahakan oleh petani baru seluas 383,7 hektar (35\%). Cara-cara usahatani yang diterapkan meliputi 3 (tiga) pola, yaitu: pola ladang seluas 63,46 hektar (16,539\%), kebun buah-buahan seluas 110,83 hektar (28,885\%) dan kebun campuran seluas 209,41 hektar (54,576\%). Sementara jumlah responden yang mengusahakan ladang sebanyak 10\% (17 responden dari jumlah sampel 175), kebun buah-buahan sebanyak 13\% (22 responden dari jumlah sampel 175) dan kebun campuran sebanyak 16\% (28 responden dari jumlah sampel 175). Selanjutnya jenis tanaman yang ditanam untuk masing-masing pola beserta persentase responden yang mengusahakan dan fokus hasil produksinya disajikan pada Tabel 4, 5 dan 6.

Tabel 4 menunjukkan jenis kacang panjang dan pisang paling diminati responden untuk diusahakan di ladang yaitu masing-masing sebesar 52,94\%, kemudian diikuti dengan buncis 47,06\%, padi dan mentimun masing-masing $41,18 \%$ dan lombok 35,29\%. Sebaliknya minat responden yang mengusahakan jenis tanaman yang lainnya (Tabel 4) sangat kurang. Alasan kecenderungan menanam dari jenis tanaman yang diminati tersebut dikarenakan tidak memerlukan perawatan yang tinggi, sehingga tentu biaya produksinya lebih sedikit. Apalagi para petani ladang umumnya memiliki dana yang terbatas untuk membeli berbagai input tanaman. Sementara itu fokus hasil produksi sebagian besar ditujukan untuk dijual (Tabel 4), kecuali untuk hasil padi.

Tabel 5 menunjukkan bahwa jenis tanaman salak paling diminati untuk diusahakan di kebun buah-buahan, yaitu sebesar 68,18\%, kemudian diikuti jenis pisang 36,36\%. Alasan jenis salak yang paling diminati dikarenakan kondisi tanah di kawasan HLSW (kawasan pemanfaatan) sangat cocok untuk tanaman tersebut. Menurut Anonymous (2003), jenis tanah yang terdapat di kawasan HLSW adalah Ultisols dan Inceptisols, namun jenis tanah Ultisols mendominasi di kawasan tersebut. Disamping itu wilayah ini sudah berkembang menjadi sentra produksi buah salak untuk Kota Balikpapan. Munculnya unit kegiatan masyarakat (UKM) melakukan pengolahan pasca panen seperti asinan buah salak menjadi nilai tambah tersendiri di wilayah tersebut. 
Tabel (Table) 4. Jenis Tanaman Ladang, Persentase Responden yang Mengusahakan dan Fokus Hasil Produksi (The Types of Plants on Swidden, Percentage of Respondents to Manage and Production Focus)

\begin{tabular}{|c|c|c|c|c|c|c|}
\hline \multirow{2}{*}{$\begin{array}{l}\text { Nomor/ } \\
\text { Number }\end{array}$} & \multirow[b]{2}{*}{ Jenis Tanaman/Types of Plants } & \multirow{2}{*}{$\begin{array}{c}\text { Total } \\
\text { Responden } \\
\text { Ladang/ } \\
\text { Number of } \\
\text { Respondents } \\
\text { for } \\
\text { Swiddener }\end{array}$} & \multirow{2}{*}{$\begin{array}{c}\text { Jumlah } \\
\text { Responden } \\
\text { yang } \\
\text { Mengusahakan/ } \\
\text { Number of } \\
\text { Respondents to } \\
\text { Manage }\end{array}$} & \multirow[b]{2}{*}{$\%$} & \multicolumn{2}{|c|}{$\begin{array}{l}\text { Fokus Hasil Produksi/ } \\
\text { Production Focus }\end{array}$} \\
\hline & & & & & $\begin{array}{c}\text { Dijual/ } \\
\text { Commercial }\end{array}$ & $\begin{array}{l}\text { Dikonsumsi/ } \\
\text { Subsistence }\end{array}$ \\
\hline 1 & Padi (Oryza sativa) & 17 & 7 & 41,18 & & X \\
\hline 2 & Kacang panjang (Vigna unguiculata) & 17 & 9 & 52,94 & $\mathrm{X}$ & \\
\hline 3 & Buncis (Phaseolus vulgaris) & 17 & 8 & 47,06 & $\mathrm{X}$ & \\
\hline 4 & Semangka (Citrullus vulgaris Schrad.) & 17 & 1 & 5,88 & $\mathrm{X}$ & \\
\hline 5 & $\begin{array}{l}\text { Lombok (bara/acar, keriting) } \\
\text { (Capsicum frutescens) }\end{array}$ & 17 & 6 & 35,29 & $\mathrm{X}$ & \\
\hline 6 & Tomat (Lycopersicum esculenta) & 17 & 2 & 11,76 & $\mathrm{X}$ & \\
\hline 7 & Mentimun (Cucumis sativus) & 17 & 7 & 41,18 & $\mathrm{X}$ & \\
\hline 8 & Terong (Solanum melongena) & 17 & 3 & 17,65 & $\mathrm{X}$ & \\
\hline 9 & Pisang (Musa paradisiaca) & 17 & 9 & 52,94 & $\mathrm{X}$ & \\
\hline 10 & Nanas (Ananas comusus Pennel) & 17 & 1 & 5,88 & $\mathrm{X}$ & \\
\hline 11 & Jagung (Zea mays) & 17 & 2 & 11,76 & $X$ & \\
\hline 12 & $\begin{array}{l}\text { Bayam } \\
\text { (Amaranthus sp.) }\end{array}$ & 17 & 1 & 5,88 & $X$ & \\
\hline 13 & $\begin{array}{l}\text { Sawi } \\
\text { (Brassica chinensis) }\end{array}$ & 17 & 1 & 5,88 & $X$ & \\
\hline
\end{tabular}

Sumber: Data Primer, 2009 (Source: Primary Data, 2009) 
Iabeı ( Iabıe) כ. Jenıs Ianaman Kebun Buan-buanan, rersentase Kesponden yang Iviengusanakan aan Fokus Hasil Produksi (The Types of Plants on Orchard, Percentage of Respondents to Manage and Production Focus)

\begin{tabular}{|c|c|c|c|c|c|c|}
\hline \multirow[b]{2}{*}{$\begin{array}{l}\text { Nomor/ } \\
\text { Number }\end{array}$} & \multirow{2}{*}{ Jenis Tanaman Types of Plants } & \multirow{2}{*}{$\begin{array}{l}\text { Total Responden } \\
\text { Kebun Buah/ } \\
\text { Number of } \\
\text { Respondents } \\
\text { for Orchard Owner }\end{array}$} & \multirow{2}{*}{$\begin{array}{l}\text { Jumlah Responden } \\
\text { yang Mengusakan/ } \\
\text { Number of } \\
\text { Respondents } \\
\text { to Manage }\end{array}$} & \multirow[b]{2}{*}{$\%$} & \multicolumn{2}{|c|}{$\begin{array}{l}\text { Fokus Hasil Produksi/ } \\
\text { Production Focus }\end{array}$} \\
\hline & & & & & $\begin{array}{c}\text { Dijual/ } \\
\text { Commercial }\end{array}$ & $\begin{array}{l}\text { Dikonsumsi/ } \\
\text { Subsistence }\end{array}$ \\
\hline 1 & Salak (Salacca zalacca) & 22 & 15 & 68,18 & $\mathrm{X}$ & \\
\hline 2 & Semangka (Citrullus vulgaris) & 22 & 1 & 4,55 & $\mathrm{X}$ & \\
\hline 3 & Pisang (Musa paradisiaca) & 22 & 8 & 36,36 & $\mathrm{X}$ & \\
\hline 4 & Elai (Durio kutejensis) & 22 & 3 & 13,64 & $\mathrm{X}$ & \\
\hline 5 & Jeruk (Citrus aurantifolia) & 22 & 1 & 4,55 & $\mathrm{X}$ & \\
\hline 6 & Rambutan (Nephelium lappaceum) & 22 & 2 & 9,09 & $\mathrm{X}$ & \\
\hline 7 & Durian (Durio zibethinus) & 22 & 1 & 4,55 & $\mathrm{X}$ & \\
\hline 8 & Cempedak (Arthocarpus integer) & 22 & 2 & 9,09 & $\mathrm{X}$ & \\
\hline 9 & Nangka (Arthocarpus integra) & 22 & 1 & 4,55 & $\mathrm{X}$ & \\
\hline
\end{tabular}

Sumber: Data Primer, 2009 (Source: Primary Data, 2009)

Berdasarkan jenis tanaman yang diusahakan terdapat 3 (tiga) kategori kebun buah yang dikembangkan oleh petani setempat. Kategori kebun yang dimaksud meliputi kebun buah tanaman semusim (semangka), kebun buah antara (pisang) dan kebun buah tanaman tahunan (salak, elai, jeruk, rambutan, durian, cempedak dan nangka). Dari 3 (tiga) kategori kebun buah yang diusahakan, ternyata kategori kebun buah tanaman tahunan mendominasi kawasan HLSW. Melihat hal ini, maka upaya masyarakat tersebut cukup memberikan keuntungan bagi penyelamatan ekosistem hutan. Dengan pola kebun buah tanaman tahunan dapat dihindari keterbukaan wilayah, sehingga dapat mengatasi kemungkinan penurunan kualitas tanah. Karena struktur kebun buah dengan tanaman tahunan sama dengan struktur hutan. Selain itu Anonymous (2008) resiko seluruh areal kebun hancur karena hama dan penyakit sangat kecil pada tanaman tahunan.

Tabel (Table) 6. Jenis Tanaman Kebun Campuran, Persentase Responden yang Mengusahakan dan Fokus Hasil Produksi (The Types of Plants on Mixed Garden, Percentage of Respondents to Manage and Production Focus)

\begin{tabular}{|c|c|c|c|c|c|c|}
\hline \multirow{2}{*}{$\begin{array}{l}\text { Nomor/ } \\
\text { Number }\end{array}$} & \multirow[b]{2}{*}{ Jenis Tanaman/Types of Plants } & \multirow{2}{*}{$\begin{array}{l}\text { Total Responden } \\
\text { Kebun Campuran/ } \\
\text { Number of Respondents } \\
\text { for Mixed Garden } \\
\text { Owner }\end{array}$} & \multirow{2}{*}{$\begin{array}{c}\text { Jumlah responden } \\
\text { yang Mengusahakan/ } \\
\text { Number of respondents } \\
\text { to Manage }\end{array}$} & \multirow[b]{2}{*}{$\%$} & \multicolumn{2}{|c|}{$\begin{array}{l}\text { Fokus Hasil Produksi/ } \\
\text { Production Focus }\end{array}$} \\
\hline & & & & & $\begin{array}{c}\text { Dijual/ } \\
\text { Commercial }\end{array}$ & $\begin{array}{c}\text { Dikonsumsi/ } \\
\text { Subsistence }\end{array}$ \\
\hline 1 & Tomat (Lycopersicum esculenta) & 28 & 8 & 28,57 & $\mathrm{X}$ & \\
\hline 2 & Lombok (Capsicum frutescens) & 28 & 10 & 35,71 & $\mathrm{X}$ & \\
\hline
\end{tabular}


Lanjutan Tabel 6

\begin{tabular}{|c|c|c|c|c|c|c|}
\hline 3 & Buncis (Phaseolus vulgaris) & 28 & 9 & 32,14 & $\mathrm{X}$ & \\
\hline 4 & $\begin{array}{l}\text { Kacang panjang (Vigna } \\
\text { unguiculata) }\end{array}$ & 28 & 13 & 46,43 & $\mathrm{X}$ & \\
\hline 5 & Pare (Momordica charantia) & 28 & 1 & 3,57 & $\mathrm{X}$ & \\
\hline 6 & Mentimun (Cucumis sativus) & 28 & 8 & 28,57 & $\mathrm{X}$ & \\
\hline 7 & Gambas (Luffa acutangula) & 28 & 1 & 3,57 & $\mathrm{X}$ & \\
\hline 8 & Durian (Durio zibethinus) & 28 & 3 & 10,71 & $\mathrm{X}$ & \\
\hline 9 & $\begin{array}{l}\text { Rambutan (Nephelium } \\
\text { lappaceum) }\end{array}$ & 28 & 9 & 32,14 & $\mathrm{X}$ & \\
\hline 10 & Sukun (Arthocarpus communis) & 28 & 2 & 7,14 & $\mathrm{X}$ & \\
\hline 11 & Karet (Hevea brasiliensis) & 28 & 6 & 21,43 & $\mathrm{X}$ & \\
\hline 12 & Salak (Salacca zalacca) & 28 & 7 & 25,00 & $\mathrm{X}$ & \\
\hline 13 & Kecapi (Sondoricum koetjape) & 28 & 1 & 3,57 & & $\mathrm{X}$ \\
\hline 14 & Sagu (Metroxylou sp.) & 28 & 1 & 3,57 & & $\mathrm{X}$ \\
\hline 15 & Pisang (Musa paradisiaca) & 28 & 12 & 42,86 & $\mathrm{X}$ & \\
\hline 16 & Cempedak (Arthocarpus integer) & 28 & 7 & 25,00 & $\mathrm{X}$ & \\
\hline 17 & Nangka (Arthocarpus integra) & 28 & 9 & 32,14 & $\mathrm{X}$ & \\
\hline 18 & Langsat (Lansicum domesticum) & 28 & 1 & 3,57 & & $\mathrm{X}$ \\
\hline 19 & Petai (Parkia speciosa) & 28 & 1 & 3,57 & & $\mathrm{X}$ \\
\hline 20 & Singkong (Monihot utilissima) & 28 & 3 & 10,71 & & $\mathrm{X}$ \\
\hline 21 & Daun sop (Apium graveolens) & 28 & 1 & 3,57 & $\mathrm{X}$ & \\
\hline 22 & Kelapa (Cocos nucifera) & 28 & 3 & 10,71 & $\mathrm{X}$ & \\
\hline 23 & Sawi (Brassica chinensis) & 28 & 1 & 3,57 & $\mathrm{X}$ & \\
\hline 24 & Kemiri (Aleurites moluccana) & 28 & 2 & 7,14 & $\mathrm{X}$ & \\
\hline 25 & Kopi (Coffea arabica) & 28 & 2 & 7,14 & $\mathrm{X}$ & \\
\hline 26 & Elai (Durio kutejenis) & 28 & 3 & 10,71 & $\mathrm{X}$ & \\
\hline 27 & Padi (Oryza sativa) & 28 & 6 & 21,43 & & $X$ \\
\hline 28 & Sahang (Piper ningrum) & 28 & 2 & 7,14 & $\mathrm{X}$ & \\
\hline 29 & Jagung (Zea mays) & 28 & 3 & 10,71 & $\mathrm{X}$ & \\
\hline 30 & Mangga (Mangifera indica) & 28 & 1 & 3,57 & & $\mathrm{X}$ \\
\hline 31 & Laos (Alpinia galanga) & 28 & 1 & 3,57 & $\mathrm{X}$ & \\
\hline 32 & Serai (Evodia suaveolens) & 28 & 1 & 3,57 & $\mathrm{X}$ & \\
\hline 33 & Terong (Solanum melongena) & 28 & 3 & 10,71 & & $\mathrm{X}$ \\
\hline
\end{tabular}

Sumber: Data Primer, 2009 (Source: Primary Data, 2009)

Tabel 6 menunjukkan bahwa jenis tanaman yang diusahakan di kebun campuran sangat bervariasi. Jenis tanaman yang diusahakan tidak hanya kelompok tanaman semusim tetapi juga kelompok tanaman tahunan/berkayu pada lahan yang sama. Kelompok tanaman tahunan/berkayu yang ditanam di wilayah itu masih terbatas pada jenis buah-buahan. Meskipun demikian, kondisi tersebut sudah menunjukkan penerapan pola dengan sistem agroforestri sudah dilakukan pada wilayah HLSW. Widianto, Wijayanto dan Suprayogo (2003) menegaskan sistem agroforestri merupakan kombinasi antara aneka jenis pepohonan dengan tanaman semusim dengan/tanpa ternak 
atau hewan. Dengan demikian sistem tersebut dapat mengoptimalkan pemanfaatan lahan, dimana saat ini kondisi lahan HLSW semakin terbatas akibat dari pertumbuhan penduduk. Lebih lanjut Paner (1975) dalam Andayani (2005) melalui penelitiannya menyatakan sistem agroforestri benar-benar memberikan keuntungan ganda, yaitu keuntungan ekonomis dan non ekonomis. Sehingga sangat cocok diterapkan pada wilayah-wilayah masyarakat setempat yang memiliki keterbatasan lahan pertanian seperti kawasan HLSW.

Disamping bercocok tanam yang dilakukan masyarakat dalam kegiatan usahataninya, juga pada lahan yang sama melakukan usaha ternak. Jenis ternak yang diusahakan disajikan pada Tabel 7.

Tabel (Table) 7. Jenis Ternak yang Terdapat pada Lahan Usahatani, Persentase Responden yang

Mengusahakan dan Fokus Hasil Produksi (The Types of Livestock on Farm Land, Percentage of

Respondents to Manage and Production Focus)

\begin{tabular}{|c|c|c|c|c|c|c|}
\hline \multirow{2}{*}{$\begin{array}{l}\text { Nomor/ } \\
\text { Number }\end{array}$} & \multirow{2}{*}{ Jenis Ternak/Types of Livestock } & \multirow{2}{*}{$\begin{array}{l}\text { Total Responden/ } \\
\text { Number of } \\
\text { Respondents }\end{array}$} & \multirow{2}{*}{$\begin{array}{l}\text { Jumlah Responden } \\
\text { yang Mengusahakan } \\
\text { Number of } \\
\text { Respondents } \\
\text { to Manage }\end{array}$} & \multirow{2}{*}{$\%$} & \multicolumn{2}{|c|}{$\begin{array}{l}\text { Fokus Hasil Produksi/ } \\
\text { Production Focus }\end{array}$} \\
\hline & & & & & $\begin{array}{c}\text { Dijual/ } \\
\text { Commercial }\end{array}$ & $\begin{array}{l}\text { Dikonsumsi/ } \\
\text { Subsistence }\end{array}$ \\
\hline \multicolumn{7}{|l|}{ Di Ladang } \\
\hline 1. & $\begin{array}{l}\text { Ayam kampung (Gallus } \\
\text { domesticus) }\end{array}$ & 17 & 11 & 64,71 & $\mathrm{x}$ & \\
\hline \multicolumn{7}{|c|}{ Di Kebun Buahbuahan - } \\
\hline 1 & $\begin{array}{l}\text { Ayam kampung (Gallus } \\
\text { domesticus) }\end{array}$ & 22 & 7 & 31,82 & $\mathrm{x}$ & \\
\hline 2 & Ikan Mas (Cyprinus carpio) & 22 & 1 & 4,55 & $\mathrm{X}$ & \\
\hline 3 & $\begin{array}{l}\text { Ikan Nila (Oreochormis } \\
\text { niloticus) }\end{array}$ & 22 & 1 & 4,55 & $\mathrm{x}$ & \\
\hline \multicolumn{7}{|c|}{ Di Kebun Campuran } \\
\hline 1 & $\begin{array}{l}\text { Ayam Kampung (Gallus } \\
\text { domesticus) }\end{array}$ & 28 & 15 & 53,57 & $\mathrm{X}$ & \\
\hline 2 & $\begin{array}{l}\text { Kambing (Capra aegagrus } \\
\text { hircus) }\end{array}$ & 28 & 1 & 3,57 & $\mathrm{X}$ & \\
\hline 3 & Ikan Mas (Cyprinus carpio) & 28 & 1 & 3,57 & $\mathrm{X}$ & \\
\hline 4 & $\begin{array}{l}\text { Ikan Nila (Oreochormis } \\
\text { niloticus) }\end{array}$ & 28 & 1 & 3,57 & $\mathrm{x}$ & \\
\hline 5 & $\begin{array}{l}\text { Ikan Gurame (Osphronemus } \\
\text { goramy) }\end{array}$ & 28 & 1 & 3,57 & $\mathrm{x}$ & \\
\hline
\end{tabular}

Sumber: Data Primer, 2009 (Source: Primary Data, 2009)

Tabel 7 menunjukkan bahwa ternak ayam kampung mendominasi ketiga pola usahatani yang dilakukan petani. Alasan ini dikarenakan, bahwa melakukan ternak ayam tidak memerlukan perawatan yang lebih seperti kambing dan ikan. Apalagi tenaga yang dikeluarkan para petani sudah terkuras dari kegiatan bercocok tanam, sehingga hal inilah yang menjadi alasan para petani lebih banyak melakukan usaha ternak ayam. Usaha ternak yang diusahakan para petani ini untuk mengoptimalkan pemanfaatan lahan, sehingga efisiensi dapat dicapai. Karena masalah utama yang dihadapi petani di wilayah ini adalah lemahnya dalam permodalan sementara biaya pokok produksi semakin meningkat. 
Hasil produksi usahatani (ladang, kebun buah-buahan dan kebun campuran) yang dilakukan petani, sebagian besar difokuskan untuk dijual baik hasil dari tanaman maupun hasil dari ternak yang diusahakan (Tabel 4, 5, 6 dan 7). Hasil penjualannya sebagai bagian dari kontribusi pendapatan rumah tangga petani digunakan untuk memenuhi kebutuhan dasar hidup yang semakin meningkat. Pada dasarnya tujuan utama bagi seorang petani adalah bagaimana dapat memenuhi kebutuhan dasarnya (Assagaf, 2004).

Produk-produk yang dihasilkan dari usahatani dijual dalam bentuk segar, sehingga petani memiliki waktu yang terbatas sebagai produk yang layak jual. Kondisi ini menunjukkan pemahaman masyarakat dalam penanganan produk pasca panen masih lemah. Tingkat pendidikan masyarakat setempat mayoritas rendah, dimana 65,90\% berpendidikan sekolah dasar ke bawah (BPHLSW, 2007 dalam Rujehan, 2010) boleh jadi salah satu penyebab lemahnya pemahaman tersebut, sehingga tidak mampu menguasai teknologi pasca panen. Petani yang mampu mendiversifikasikan hasil usahataninya (menghasilkan produk olahan) melalui penguasaan teknologi pasca panen dapat mencegah kerugian bila terjadi distorsi harga. Kastaman (2005) menyatakan, bahwa petani yang menjual hasil usahataninya dalam bentuk segar sangat rentan terhadap kerugian manakala ada distorsi pada pasar. Dengan demikian, pemanfaatan teknologi pasca panen bagi petani dapat memberikan kontribusi pendapatan yang lebih berarti lagi.

Meskipun demikian terhadap fenomena di atas, namun secara keseluruhan kontribusi nilai manfaat yang diberikan HLSW untuk mendukung pendapatan rumah tangga petani masyarakat setempat ternyata cukup tinggi. Hasil penelitian Rujehan dkk. (2010) menyatakan sebesar 54,18\% dari total pendapatan rumah tangga dipenuhi dari pemanfaatan kawasan HLSW. Kontribusi tersebut diperoleh dari upaya usahatani (41\%), pemanfaatan unsur biologi (2.03\%) dan pemanfaatan unsur ekologi (11,15\%). Kontribusi yang diberikan tersebut sangat berarti ketika saat ini peluang mendapatkan pekerjaan lain semakin terbatas di wilayah studi.

\section{KESIMPULAN}

HLSW adalah tipe hutan Dipterokarpa dataran rendah, di dalamnya terdapat berbagai komponen unsur biologi dan unsur ekologi yang telah dimanfaatkan masyarakat setempat. Komponen unsur biologi yang dimanfaatkan masyarakat tersebut sebagian besar diperuntukkan untuk dikonsumsi sendiri. Hasil-hasil yang diperoleh meliputi: kayu untuk kayu bakar sebagai sarana memasak, daun nipah untuk atap, rotan dan bambu sebagai penunjang pembuatan atap, tumbuhan obat dimanfaatkan ketika sakit, rumput/pakan ternak untuk makanan ternak, lebah madu sebagai penghasil madu, gaharu untuk acara ritual keagamaan, buah-buahan untuk makanan satwa dan sebagian dikonsumsi masyarakat, sayur-sayuran maupun ikan untuk melengkapi menu masakan rumah tangga dan kayu untuk bahan bangunan sebagai sarana membangun pondok. Sementara komponen unsur ekologi yang dimanfaatkan masyarakat setempat adalah berupa air yang bersumber dari sumur, waduk dan sungai, 
serta lahan pertanian. Air dimanfaatkan untuk mandi cuci kakus (MCK) dan air minum, sedangkan lahan pertanian yang subur digunakan untuk kegiatan usahatani.

Namun dari waktu ke waktu nilai manfaat langsung HLSW tersebut di atas telah mendapat tekanan yang cenderung meluas. Hal ini diantaranya disebabkan oleh adanya peningkatan populasi masyarakat setempat. Dalam periode 2002-2007, populasi masyarakat meningkat 35,58\% sehingga dapat mempengaruhi kelestarian HLSW sebagai sumber unsur biologi dan unsur ekologi yang dimaksud. Oleh karena itu BPHLSW perlu segera melakukan suatu tindakan yang tepat untuk mengatasinya. Tindakan yang dapat dilakukan oleh BPHLSW diantaranya dengan melibatkan masyarakat setempat yang lebih intensif dalam segala aspek kegiatan, mulai perencanaan hingga pengawasan/pengamanan hutan.

Selanjutnya hasil-hasil dari kegiatan usahatani termasuk ternak untuk ketiga pola (ladang, kebun buah-buahan dan kebun campuran) sebagian besar difokuskan untuk dijual (bersifat produktif) meskipun ada sebagian kecil yang dikonsumsi sendiri (bersifat konsumtif). Kecenderungan ini karena masyarakat setempat sebagai petani adalah masyarakat pendatang (migran) yang memiliki sifat-sifat komersial, sehingga upaya meningkatkan pendapatan menjadi tujuan utama. Ditambah lagi dengan posisi HLSW yang dekat dengan Kota Balikpapan yang banyak menyediakan barang-barang konsumtif yang memerlukan dana untuk mendapatkannya.

Untuk memenuhi fenomena di atas tentu diperlukan pengaturan atau tindakan manajemen untuk meningkatkan nilai produksi yang dihasilkan dan berkelanjutan. Sistem pengelolaan lahan yang optimal seperti penerapan pola agroforestri menjadi suatu alternatif ke arah itu. Karena dengan pola agroforestri tidak hanya memperoleh manfaat ekonomi dari tanaman ataupun ternak yang dihasilkan, tetapi juga dapat menjamin kualitas lahan menjadi tetap produktif mengingat pola tersebut seperti pola hutan, sehingga kelestarian manfaat ekonomi tetap dapat dicapai. Berdasarkan itu, maka HLSW dengan keberadaan kawasan pemanfaatan yang dimilikinya sayogianya strategi pengelolaan lahan dengan konsep agroforestri dapat diandalkan untuk menuju pelestarian lingkungan dan mensejahterakan masyarakat khususnya masyarakat setempat. Menciptakan keseimbangan kepentingan ekologi dan ekonomi dalam pengelolaan HLSW adalah suatu strategi yang sayogianya dicapai ke depan.

\section{DAFTAR PUSTAKA}

Andayani, W. 2005. Ekonomi Agroforestri. DEBUT Press, Jogjakarta. pp. 113

Anonymous. 2003. Pembagian Blok Pengelolaan Kawasan Hutan Lindung Sungai Wain Balikpapan.

Badan Pengelola Hutan Lindung Sungai Wain, Kota Balikpapan. pp. 47

2004. Peraturan Daerah (PERDA) Hutan Lindung Sungai Wain (HLSW) No. 11 Tahun

2004. Pemerintah Daerah Kota Balikpapan, Balikpapan. pp. 21

. 2008. Forum Kerjasama Agribisnis. 
http://foragri.blogsome.com/buah-buahan-tanaman-tahunan/

2010. Hutan Lindung Sungai Wain (Fungsi dan Potensi). Badan Pengelola Hutan Lindung Sungai Wain.

http://sungaiwain.org/profil-hlsw/fungsi-dan-potensi-hlsw

Assagaf, D. 2004. Peluang Peningkatan Pendapatan Petani (Analisis Manfaat dan Biaya serta Resiko). Institut Pertanian Bogor (IPB), Bogor. pp. 20

Kastaman, R. 2005. Upaya Peningkatan Pendapatan Petani yang Maksimal Melalui Pengaturan Pola Pemilihan Komoditas Model Sinergi (Studi Kasus di Kecamatan Cibiru Kota Bandung). Fakultas Teknologi Industri Pertanian Universitas Padjadjaran, Bandung. pp. 15

http://resources.unpad.ac.id/unpad-content/uploads/publikasi_dosen/No.20\%20Jurnal\%20sosiohum aniora\%20-\%20Vol\%209\%20No.3\%202007.pdf

Nugroho, B.T.A., N.K.E. Undaharta dan M. Siregar. 2008. Interaksi Masyarakat Sekitar Hutan terhadap Pemanfaatan Keanekaragaman Hayati di Kawasan Ekosistem Hutan Alami Bedugul-Pancasari, Bali. UPT. Balai Konservasi Tumbuhan Kebun Raya Eka Karya Bali, Lembaga Ilmu Pengetahuan Indonesia (LIPI), Tabanan. pp. 5

http://www.unsjournals.com/D/D0903/D090316.pdf

Parel, C.P., G.C. Caldito, P.L. Ferrer, G.G. De Guzman, C.S. Sinsioco, and R.H. Tan. 1973. Sampling Design and Procedures. The Agricultural Development Council, Quezon City. pp. 53

Rujehan, Soemarno, K. Hidayat dan M. Mustadjab. 2010. Nilai Ekonomi Hutan Lindung Sungai Wain (HLSW) Bagi Masyarakat Setempat. AGRITEK Vol.18 No.1 Hal. 1-175 Januari 2010. Jurnal Ilmu-ilmu Pertanian, Teknologi Pertanian dan Kehutanan. Lembaga Penelitian dan Pengabdian pada Masyarakat Institut Pertanian Malang, Malang. pp. 11

Rujehan. 2010. Pengelolaan Kawasan Hutan Lindung Sungai Wain (HLSW) Kalimantan Timur.

Disertasi Fakultas Pertanian Universitas Brawijaya, Malang. pp. 261

Simon, H. 1993. Hutan Jati dan Kemakmuran. Aditya Media, Yogyakarta.

Soekartawi. 1995. Analisis Usaha Tani. Penerbit UI Press, Jakarta.

Uluk, A., M. Sudana dan E. Wollenberg. 2001. Ketergantungan Masyarakat Dayak Terhadap Hutan (Di Sekitar Taman Nasional Kayan Mentarang). Center for International Forestry Research (CIFOR), Bogor. pp. 150

Widayanti, W.T. dan S. Widodo. 1999. Pemerataan dan Pemanfaatan Pendapatan Keluarga Petani Hutan. Jurnal Hutan Rakyat Vol.1 No.1 Th.1999. Pusat Kajian Hutan Rakyat (Center for Community Forestry Studies) Fakultas Kehutanan UGM, Yogyakarta. pp. 21

Widianto, N. Wijayanto, dan D. Suprayogo. 2003. Pengelolaan dan Pengembangan Agroforestri. Bahan Ajaran Agroforestri 6. World Agroforestry Centre (ICRAF), Bogor. pp. 24 